\title{
Electroencephalography-driven approach
} to prodromal Alzheimer's disease diagnosis: from biomarker integration to network-level comprehension

\author{
This article was published in the following Dove Press journal: \\ Clinical Interventions in Aging \\ 6 July 2016 \\ Number of times this article has been viewed
}

\section{Davide Vito Moretti}

Rehabilitation in Alzheimer's Disease Operative Unit, IRCCS San Giovanni di Dio, Fatebenefratelli, Brescia, Italy
Correspondence: Davide Vito Moretti Rehabilitation in Alzheimer's Disease Operative Unit, IRCCS San Giovanni di Dio, Fatebenefratelli, via Pilastroni, 25/25 Brescia, Italy

Tel +390303501597

$\mathrm{Fax}+3903035335 \mathrm{I} 3$

Email davide.moretti@afar.it
Abstract: Decay of the temporoparietal cortex is associated with prodromal Alzheimer's disease (AD). Additionally, shrinkage of the temporoparietal cerebral area has been connected with an increase in $\alpha 3 / \alpha 2$ electroencephalogram (EEG) power ratio in prodromal AD. Furthermore, a lower regional blood perfusion has been exhibited in patients with a higher $\alpha 3 / \alpha 2$ proportion when contrasted with low $\alpha 3 / \alpha 2$ proportion. Furthermore, a lower regional blood perfusion and reduced hippocampal volume has been exhibited in patients with higher $\alpha 3 / \alpha 2$ when contrasted with lower $\alpha 3 / \alpha 2$ EEG power ratio. Neuropsychological evaluation, EEG recording, and magnetic resonance imaging were conducted in 74 patients with mild cognitive impairment (MCI). Estimation of cortical thickness and $\alpha 3 / \alpha 2$ frequency power ratio was conducted for each patient. A subgroup of 27 patients also underwent single-photon emission computed tomography evaluation. In view of $\alpha 3 / \alpha 2$ power ratio, the patients were divided into three groups. The connections among cortical decay, cerebral perfusion, and memory loss were evaluated by Pearson's $r$ coefficient. Results demonstrated that higher $\alpha 3 / \alpha 2$ frequency power ratio group was identified with brain shrinkage and cutdown perfusion inside the temporoparietal projections. In addition, decay and cutdown perfusion rate were connected with memory shortfalls in patients with MCI. MCI subgroup with higher $\alpha 3 / \alpha 2$ EEG power ratio are at a greater risk to develop $\mathrm{AD}$ dementia.

Keywords: prodromal AD, EEG, SPECT, MRI, alpha rhythm, hippocampal atrophy

\section{Introduction}

Patients with mild cognitive impairment (MCI) normally belong to the group with a noteworthy risk of developing Alzheimer's disease (AD). As a consequence, there is a need to find biomarkers that allow characterization of individuals who might just be at considerable risk of expressing the disease, and are prone to be profitable for early investigation and accommodation of counteractive action cures. The recognizable proof and acceptance of biomarkers for diagnosing, observing progression, and anticipating the onset of $\mathrm{AD}$ has been a most critical for the last 10 years. In accordance with genuine demonstrative criteria, it has been identified that the blending of various biomarkers is an identifier for a correct and early anticipation of AD. ${ }^{1,2}$ Thus, remarkably, the most affirmed biomarkers are Abeta42 and tau protein in the cerebrospinal fluid, glucose hypometabolism measured by fluorodeoxyglucose positron emission tomography, decay of hippocampal volume on magnetic 
resonance imaging (MRI), and brain amyloid burden measured by imaging with positron emission tomography. ${ }^{3,4}$ However not all controversies are clarified. The present biomakers are able to detect patients with neurodegenerative disease but they lack the mandatory specificity for the diagnosis of particular subtypes of dementia. Most studies of recent MRI examinations have demonstrated widespread neural system changes in patients with prodromal AD. ${ }^{5-10}$ Particularly, patients with cognitive decline show early decay and absence of gray matter specifically in cortical zones, ${ }^{6,8}$ precuneus, hippocampal, middle temporal, and parietal lobes. For identifying biomarkers for an early and prescient analysis, the electroencephalogram (EEG) is a reliable tool. ${ }^{11}$ Unquestionably, it is widely perceived that the cerebral EEG rhythms reflect the basic brain system condition. ${ }^{12}$ Generally, the $\alpha$ rhythm seems to be a suitable instrument to recognize the relationship between structural and functional brain networks. ${ }^{13-16}$ Recent investigations have shown that the increase in upper $\alpha$ with respect to lower $\alpha$ frequency is typically a trusted EEG marker of hippocampal decay. ${ }^{17,18}$ Similarly, the expansion inside the $\alpha 3 / \alpha 2$ power ratio has been exhibited as a prescient of identification of patients with MCI due to AD, but not non-AD dementia. ${ }^{19-24}$ Moreover, patients with higher $\alpha 3 / \alpha 2$ showed a reduced blood regional cerebral perfusion pattern when compared with patients with lower $\alpha 3 / \alpha 2$ power ratio. In this study, the relationship between memory, and both MRI and single-photon emission computed tomography (SPECT) estimations inside the MCI group with a greater $\alpha 3 / \alpha 2$ power ratio was examined. Results show that in the higher $\alpha 3 / \alpha 2$ group, memory loss was related to cortical decay and reduction in local cerebral perfusion within the temporoparietal cortex.

\section{Patients and methods}

\section{Patients}

In this study, 74 patients with MCI were enrolled from the memory clinic of the Scientific Institute for Research and Care of Alzheimer's and Psychiatric Disease (Fatebenefratelli) in Brescia, Italy. All research protocols were approved by the Ethics Committee of the Istituzioni Ospedaliere Cattoliche. Written informed consent was obtained from all individuals or their relatives, in agreement with the Code of Ethics of the World Medical Association (Declaration of Helsinki).

\section{Diagnostic criteria}

Diagnostic and severity assessment instruments used were as follows: the mini-mental state examination (MMSE), ${ }^{25}$ the clinical dementia rating scale, ${ }^{26}$ the Hachinski ischemic scale, ${ }^{27}$ the instrumental and basic activities of daily living, ${ }^{28}$ and a complete neuropsychological appraisal. ${ }^{29}$ Depressive symptoms were surveyed using the Center for Epidemiological Studies-Depression (CES-D) scale. ${ }^{30}$ All the neuropsychological examinations were standardized to the Italian population with respect to age, education, and sex. Patients had an MMSE score ranging between 25 and 30/30, without any functional impairment. Correspondingly, patients underwent MRI and laboratory tests to identify if there were other reasons for the cognitive failure. Sociodemographic and cognitive features are outlined in Table 1. There was no statistical distinction in age, sex, and education among the study groups.

Table I Demographic and cognitive characteristics of the whole sample, disaggregated for increased levels of $\alpha 3 / \alpha 2$

\begin{tabular}{|c|c|c|c|c|}
\hline & \multicolumn{4}{|l|}{$\alpha 3 / \alpha 2$} \\
\hline & High & Middle & Low & P-value \\
\hline \multicolumn{5}{|l|}{ Demographic and clinical futures } \\
\hline Number of patients & 18 & 38 & 18 & \\
\hline Age (years) & $70.4 \pm 6.7(60-85)$ & $68.4 \pm 8.2(52-83)$ & $70.4 \pm 7.4(57-80)$ & 0.55 \\
\hline Sex (female) & $13(\%)$ & $24(\%)$ & $14(\%)$ & 0.51 \\
\hline Education (years) & $6.6 \pm 3.6(4-18)$ & $7.6 \pm 3.7(3-17)$ & $8.3 \pm 4.7(3-18)$ & 0.42 \\
\hline Mini-mental state examination & $27 \pm 1.7(25-29)$ & $27.4 \pm I .3(25-30)$ & $26.9 \pm 1.2(25-30)$ & 0.46 \\
\hline WMHs $\left(\mathrm{mm}^{3}\right)$ & $2.78 \pm 2.58$ & $5.59 \pm 6.60$ & $2.57 \pm 2.76$ & 0.09 \\
\hline$\alpha 3 / \alpha 2$ & $1.29 \pm 0.1(1.17-1.52)$ & $1.08 \pm 0.0(1-1.16)$ & $0.9 \pm 0.1(0.77-0.98)$ & 0.000 \\
\hline \multicolumn{5}{|l|}{ Memory } \\
\hline Babcock & $9.6 \pm 3.5$ & $9.8 \pm 4.1$ & $9.9 \pm 3.8$ & 0.99 \\
\hline AVLT immediate recall & $42.7 \pm 7.6$ & $38.8 \pm 11.8$ & $40.5 \pm 12.8$ & 0.53 \\
\hline AVLT delayed recall & $8.6 \pm 3.2$ & $8.2 \pm 4.1$ & $9.1 \pm 4.4$ & 0.80 \\
\hline
\end{tabular}

Notes: Numbers denote mean \pm standard deviation and number (range). $P$ denotes significance on ANOVA.

Abbreviations: ANOVA, analysis of variance; AVLT, auditory verbal learning test; WMHs, white matter hyperintensities. 


\section{EEG recordings}

The EEG was recorded constantly for 5 minutes, with patients relaxing with eyes closed in a comfortable chair, using electrode elastic cups (Electro-Cap, Inc., Eaton, OH, USA) on 19 sites, in accordance with the 10-20 international system (Fp1, Fp2, F7, F3, Fz, F4, F8, T3, C3, Cz, C4, T4, T5, P3, Pz, P4, T6, O1, and O2). To maintain the level of vigilance standard, an operator controlled the patients and the EEG at the same time, alerting the patients whenever there were markers of behavioral and/or EEG tiredness. The ground electrode was situated before Fz. The left and right mastoids served as the reference components. The recordings were utilized to re-reference the scalp recordings to the common average. Information was recorded with a bandcross channel of $0.3-70 \mathrm{~Hz}$ and digitized at a testing rate of $250 \mathrm{~Hz}$ (BrainAmp; BrainProducts, Munich, Germany). Terminal skin impedance was set under $5 \mathrm{k} \Omega$. Ocular movements were detected by electrooculogram. The recording was conducted for 5 minutes to assure the stationarity of the signal and minimize the presence of artifacts. EEG information was then fragmented in successive epochs for 2 seconds with a frequency resolution of $0.5 \mathrm{~Hz}$. The mean number of epochs was 140; range 130 to 150 . The presence of ocular, muscular and other type of artifacts were manually checked by two skilled electroencephalographists. ${ }^{15}$

\section{Investigation of individual frequency bands}

A computerized fast Fourier transform (FFT) dependent electrical power spectrum assessment (Welch method, Hanning windowing, and no phase shift) was used to compute the power density of EEG rhythms (extending from $2 \mathrm{~Hz}$ to $45 \mathrm{~Hz}$ ), which has a $0.5 \mathrm{~Hz}$ resolution. Two landmark frequencies (the $\theta / \alpha$ transition frequency [TF] and the individual $\alpha$ frequency [IAF] peak) were chosen in agreement with previous literature. ${ }^{16,19}$ IAF and TF were estimated for every patient. These landmark frequencies were evaluated on the power spectra averaged via all recording electrodes. This "collapsed power methodology", staying global field potential permits to steadily individuate the IAF. Using TF and IAF, we evaluated the frequency band array for every individual as follows: $\delta$ from TF- 4 to TF-2, $\theta$ from TF- 2 to TF, lower $\alpha$ band ( $\alpha 1$ and $\alpha 2)$ from TF to IAF, and upper $\alpha$ band (or $\alpha 3$ ) from IAF to IAF + two. The $\alpha 1$ and $\alpha 2$ teams were processed as required after: $\alpha 1$ from TF toward the mid-level of TF-IAF range and $\alpha 2$ from this mid-position for the IAF prime. The mean frequency assortment processed in patients with MCI is as follows: $\delta 2.9-4.9 \mathrm{~Hz} ; \theta 4.9-6.9 \mathrm{~Hz}$; $\alpha 16.9-8.9 \mathrm{~Hz} ; \alpha 28.9-10.9 \mathrm{~Hz}$; and $\alpha 310.9-12.9 \mathrm{~Hz}$. Ultimately, the relative power for each frequency band was computed, given the ratio among the absolute power in every frequency and the absolute power spectra in the total frequency range (from $2 \mathrm{~Hz}$ to $45 \mathrm{~Hz}$ ). The $\alpha 3 / \alpha 2$ power proportion was estimated in all patients, and three groups were already identified with regard to increasing tertile estimations of $\alpha 3 / \alpha 2$ : low $(\alpha 3 / \alpha 2<1)$, middle $(1<\alpha 3 / \alpha 2<1.16)$, and high $(\alpha 3 / \alpha 2>1.16)$. The tertile division gives a balanced composition of the groups to analyze.

\section{MRI estimations}

For each patient, a high-resolution sagittal T1-weighted volumetric MRI output was acquired at the Neuroradiology Unit of the "Città di Brescia" Medical Center, Brescia, Italy, with a $1.0 \mathrm{~T}$ Philips Gyroscan scanner by using a gradient echo three-dimensional approach: $\mathrm{TR}=20 \mathrm{~ms}$, TE $=5 \mathrm{~ms}$, flip edge $=30$, field of check out $=220 \mathrm{~mm}$, acquisition matrix $=256 \mathrm{~mm} \times 256 \mathrm{~mm}$, and slice thickness $=1.3 \mathrm{~mm}$. Cortical thickness estimations for 74 patients with MCI were made using a computerized MRI-based assessment method: FreeSurfer v5.1.0, a tool for programming instruments for the study of cortical and subcortical constructions. In the cortical surface, the units on the limit between white and cortical gray that make a difference and the pial surface were also traced. In addition, a primarily cortical surface-based atlas was delineated. Surfaces from patients could also be adjusted to this atlas using a large-dimensional, nonlinear algorithm. ${ }^{31}$ For each patient, the T1-weighted, anatomical three-dimensional MRI dataset file was converted from DICOM to. mgz format. Following this, the pinnacle used for stripping utilizing a deformable format design, and extracerebral voxels was deleted. Cortical thickness was estimated by utilizing the area between these surfaces (white and pial surfaces) at $\sim 160,000$ focuses for each hemisphere in the cortical mantle. Therefore, the pial floor of each individual patient was inflated to determine the huge-scale folding designs of the cortex and subsequently transformed into a sphere to minimize metric distortion. The individual folding patterns of the area were then aligned with a mean folding pattern using superior-resolution area-based averaging. Thickness measures were mapped for the inflated surface area of each participant's brain reconstruction allowing for visualization of knowledge over the overall cortical floor. Finally, cortical thickness was smoothed, having a $20 \mathrm{~mm}$ entire width at half height Gaussian kernel to lessen the variations while measuring for further analysis. 


\section{SPECT scans}

A total of 27 patients with MCI and 17 healthy controls underwent SPECT scan in the Nuclear Medicine Department of the United Hospitals, Bergamo, Italy. Each patient was offered an intravenous injection of $925 \mathrm{MBq}$ of technetium-99m ethyl cysteinate compound under resting circumstances, lying supine with eyes closed inside a peaceful, dimly lit space. Forty to 60 minutes after the injection, brain SPECT was executed utilizing a dual-head rotating gamma digital camera (General Electrics, Elscint Helix, Wauwatosa, WI, USA) equipped with low energy, high resolution, parallel hole collimators. A $128 \times 128$ pixel matrix, zoom $\times 1.5$ was used for graphic acquisition using 120 sites around a $360^{\circ}$ orbit (in $3^{\circ}$ approaches), which has a pixel sizing and slice thickness of $2.94 \mathrm{~mm}$. Butterworth filter back projection (acquire $=7$, cutoff $=0.45 \mathrm{cycles} / \mathrm{cm}$ ) was used for picture reconstruction, and attenuation correction was executed employing Chang's methodology (attenuation coefficient $=0.11 / \mathrm{cm}$ ). Images were exported in DICOM structure. To accumulate a particular standardization, we developed a study-precise SPECT style and design adopting both SPECT and MRI scans equally, for all patients and healthy controls during the overview, using a technique represented comprehensively in other studies. ${ }^{31}$ Briefly, we created a personalized superior-definition MRI guideline, regenerated SPECT scans from the construction adopted by MRIcro, and then coregistered them for their specific MRI scans with statistical parametric mapping, Version 2 (SPM2; Functional Imaging Laboratory, London, UK). We normalized each MRI per the personalized MRI information. By means of a nonlinear transformation (slice $25 \mathrm{~mm}$ ), after which we utilized the standardization parameters for the coregistered SPECT. The personalized SPECT was regarded as being the standard of all normalized SPECT scans. All scans were processed through the SPM2 program. The regions of interest selected for perfusion analyses in each hemisphere with the select atlas were as follows: frontal, parietal, temporal lobes, thalamus, and hippocampalamygdalar complex. ${ }^{31}$

\section{MRI statistical investigation}

Distinctions between groups sociodemographic and neuropsychological characteristics were analyzed making use of SPSS v13.0 (SPSS Inc., Chicago, IL, USA), accomplishing an analysis of variance (ANOVA) for continual variables and paired $\chi^{2}$ examination for dichotomous variables. For continuous variables, post hoc pairwise comparisons among groups were executed with Games-Howell or Bonferroni tests, depending on the homogeneity of variance analyzed with Levene's test. For the neuroimaging analysis, the Qdec interface in FreeSurfer application was used; a vertex-by-vertex evaluation was carried out by a general linear model to analyze whether any change in mean cortical thickness existed among the groups (low: $\alpha 3 / \alpha 2<1 \mu \mathrm{V}^{2}$; center: $1<\alpha 3 / \alpha 2<1.16 \mu \mathrm{V}^{2}$; and high: $\left.\alpha 3 / \alpha 2>1.17 \mu \mathrm{V}^{2}\right)$. Subsequent comparisons were carried out as follows: higher vs lower, higher vs middle, and middle vs lower. Age, sex, education, general cognitive degree (MMSE rating), and white matter hyperintensities (WMHs) were considered as covariates in the analysis to avoid confounding factors. We first attempted to use a Bonferroni multiple-comparison correction for our assessment (at $P<0.05$, corrected); however, no $P$-value survived after this correction. Therefore, we elected to establish a far more restrictive significance threshold than $P<0.05$, corrected, at $P<0.001$ uncorrected, for various comparisons. In addition, we regarded as sizeable only the clusters that were also $\geq 30 \mathrm{~mm}^{2}$. Finally, a surface map was created to display the final results on an average brain. For illustrative aims, significance was set at $P<0.01$, uncorrected for various comparisons.

\section{SPECT statistical assessment}

All the statistical analyses employed in this study were executed by SPSS software method Version 13.0. First, the distinctions regarding sociodemographic, scientific, and cognitive variables in the two groups (MCI at reduced, and MCI AT significant chance to transform in AD) were investigated. The $\chi^{2}$ test for categorical variables (sex and ApoE carriers) and Student's independent $t$-test for continuous variables (volumetric, perfusion values, and EEG frequencies) were used. In all analyses, the significance threshold was set at $P<0.05$. Individual SPECT scans were coregistered to their own MRI pictures, and the SPECT design and style were also coregistered into the higher definition MRI template, every normalized SPECT and MRI picture used for the statistical investigation was coregistered into the SPM customary anatomical spot. Pearson's $r$ correlations were assessed among the selected perfusion regions of interest (with regard to age-corrected $W$ scores) and the EEG frequencies in each subgroup.

\section{Memory performance statistical assessment}

In order to obtain a control assessment to exclude casual interactions among EEG markers and cortical volumes, 
a correlation between brain cortical atrophy and memory general performance was examined. The correlation test was completed within the three samples independently (higher $\alpha 3 / \alpha 2$, lower $\alpha 3 / \alpha 2$, and middle $\alpha 3 / \alpha 2$ ratios) and on the entire sample. The measure of a linear correlation was led by our a priori hypotheses, for which the MCI subgroup with the bigger cortical thinning and major increase in $\alpha 3 / \alpha 2$ EEG ratio (indicating an incipient AD) definitely should exhibit a clear correlation, along with memory loss. The correlation analysis was carried out with the following memory tests: Babcock test, Rey auditory verbal learning test (AVLT) rapid recall, and Rey AVLT delayed recall. The analysis threshold was at $P<0.001$, corrected for numerous comparisons. The outcomes were mapped at $P<0.005$, uncorrected for illustrative aims. The clusters that survived while using the statistical threshold and were $\geq 15 \mathrm{~mm}^{2}$ were seen as significant.

\section{Results}

\section{MRI}

Table 1 demonstrates the sociodemographic and neuropsychological characteristics of MCI subgroups obtained through the tertile estimations of $\alpha 3 / \alpha 2$ EEG frequency power ratio. The ANOVA investigation showed that there were no significant contrasts between groups matched for age, sex, WMHs load, education, or general cognitive level. In addition, age, sex, education, general cognitive stage (MMSE rating), and WMHs were used as covariates within the ensuing examination to abstain from confounding variables. $\alpha 3 / \alpha 2$ power ratio was significant, estimated via Games-Howell post hoc correlations $(P<0.0001)$. No different significant results were obtained within the comparisons of the remaining EEG frequency bands.

\section{Differences in cortical thickness between groups}

1. High vs low: compared with low $\alpha 3 / \alpha 2$, patients with high $\alpha 3 / \alpha 2$ ratio exhibited a decrease in the bilateral temporal, supramarginal, and precuneus cortices and in the right inferior parietal and insular cortex. Global cortical gray matter decrease in the high $\alpha 3 /$ $\alpha 2$ compared with the low $\alpha 3 / \alpha 2$ groups was $471 \mathrm{~mm}^{2}$ (Figure 1).

2. High vs middle: compared with the middle $\alpha 3 / \alpha 2$ group, the areas of decay were established in the left supramarginal gyrus, left precuneus, and left postcentral cortex. A decrease in the global cortical gray matter within the higher $\alpha 3 / \alpha 2$ group compared with the middle $\alpha 3 / \alpha 2$ group was $160 \mathrm{~mm}^{2}$ (Figure 2), which was 34\% less than that in the low $\alpha 3 / \alpha 2$ ratio group.

No significant cortical thickness differences were observed between middle and low $\alpha 3 / \alpha 2$ groups.

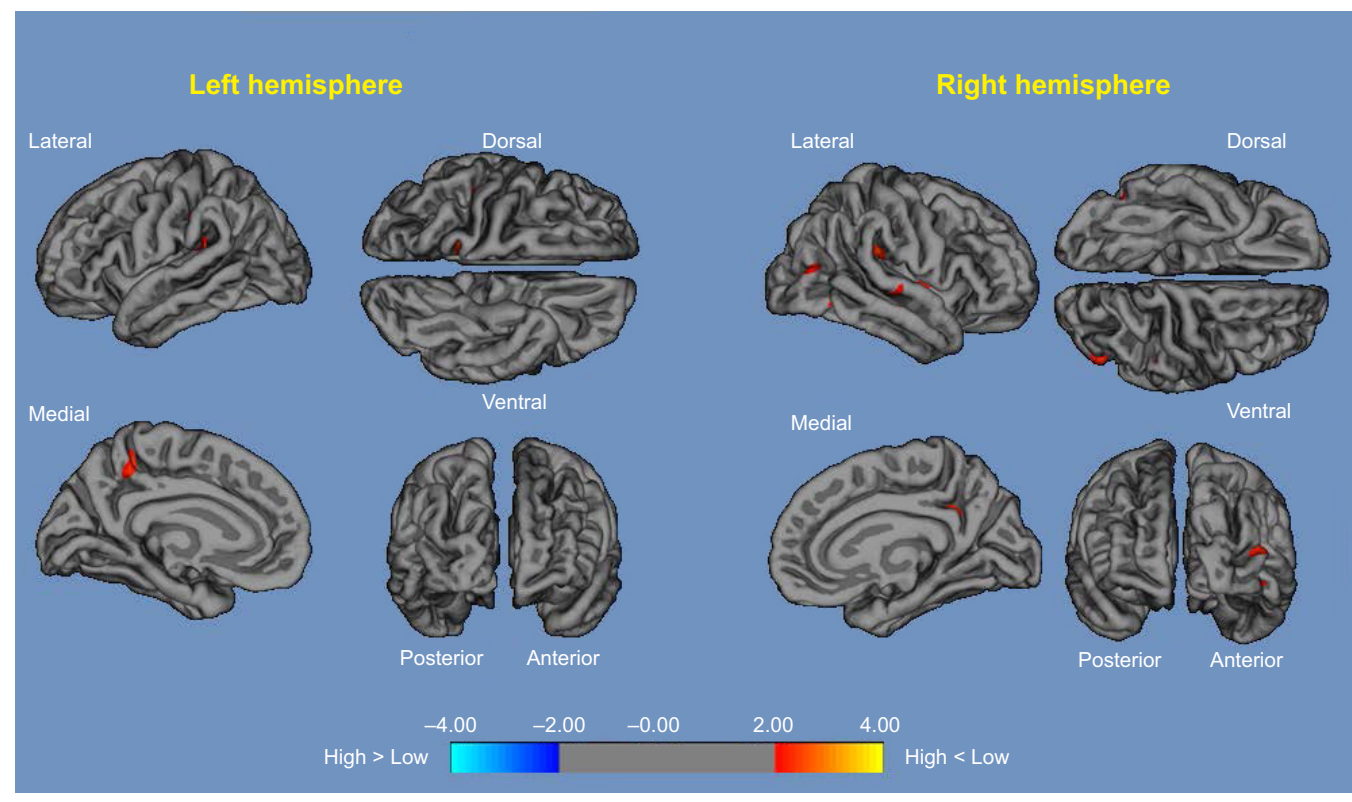

Figure I High $\alpha 3 / \alpha 2$ vs low $\alpha 3 / \alpha 2$.

Notes: Red color represents the brain regions with higher regional cortical thickness in patients with $\mathrm{MCl}$ with high $\alpha 3 / \alpha 2$ ratio compared to patients with $\mathrm{MCl}$ with low $\alpha 3 / \alpha 2$ ratio $(P<0.01$, uncorrected). The color coding for $P$-values is on a logarithmic scale. Results are presented on the pial cortical surface of the brain; dark gray regions represent sulci and light gray regions represent gyri.

Abbreviation: $\mathrm{MCl}$, mild cognitive impairment. 


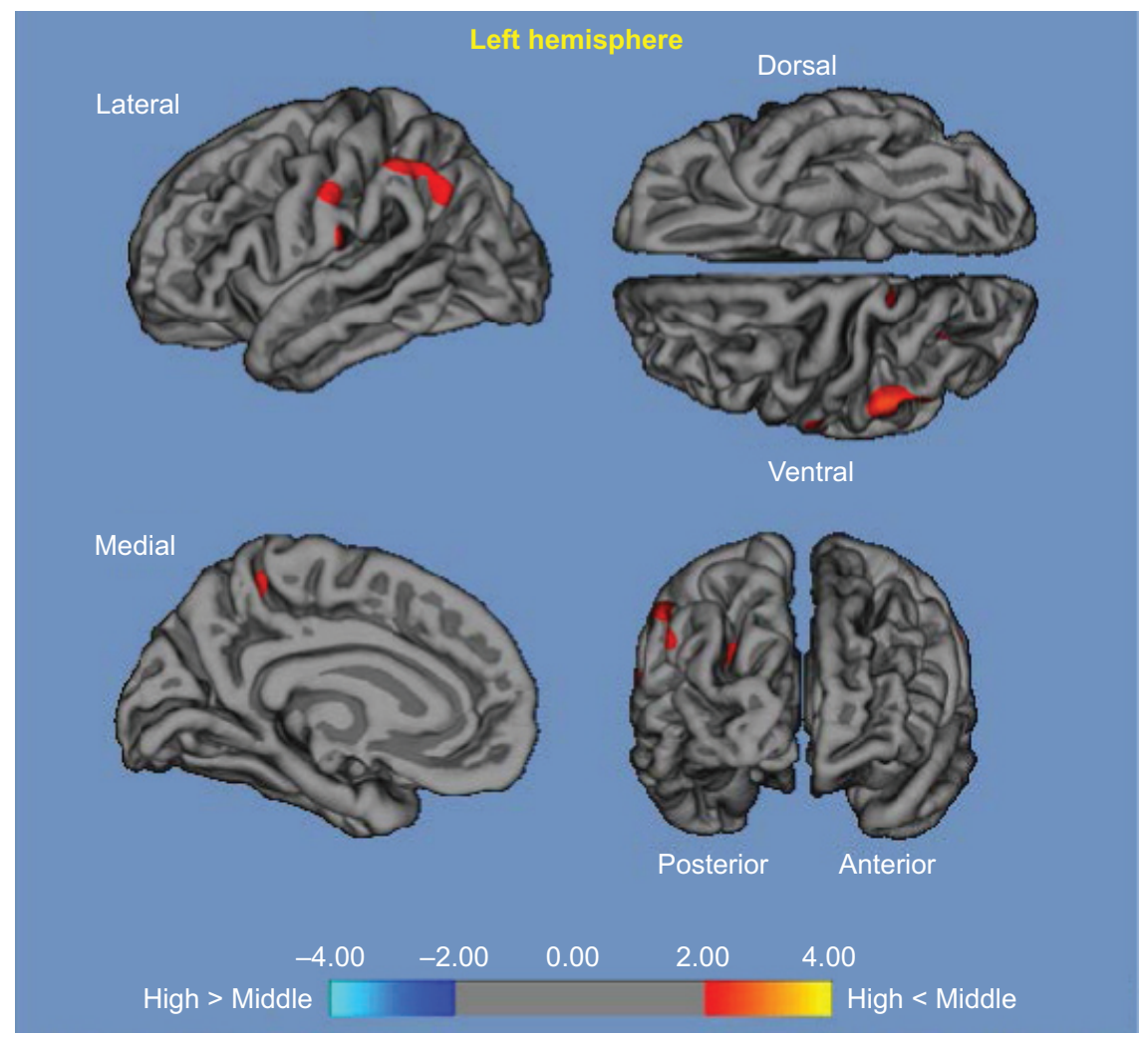

Figure 2 High $\alpha 3 / \alpha 2$ vs middle $\alpha 3 / \alpha 2$.

Notes: Red color represents the brain regions with higher regional cortical thickness in patients with $\mathrm{MCl}$ with high $\alpha 3 / \alpha 2$ ratio compared to patients with $\mathrm{MCl}$ with middle $\alpha 3 / \alpha 2$ ratio $(P<0.01$, uncorrected). The color coding for $P$-values is on a logarithmic scale. Results are presented on the pial cortical surface of the brain; dark gray regions represent sulci and light gray regions represent gyri.

Abbreviation: $\mathrm{MCl}$, mild cognitive impairment.

\section{Correlations between memory assessments and cortical thickness}

1. Babcock test: in the higher $\alpha 3 / \alpha 2$ group, a significant correlation was observed with thickness values within the left middle frontal cortex $(r=0.80, P=0.0001)$, left inferior temporal cortex $(r=0.72, P=0.0001)$, and right middle frontal cortex $(r=0.74, P=0.00$; Figure 3$)$.

2. AVLT immediate recall: within the higher $\alpha 3 / \alpha 2$ group, a significant correlation was observed with the cortical thickness values within the left and right precuneus (left $r=0.78, P<0.000$; right $r=0.72, P=0.007$ ), left fusiform cortex ( $r=0.76, P=0.0005)$, inferior parietal $(r=0.74, P=0.0001)$, inferior temporal cortex $(r=0.71$, $P=0.0008)$, and superior temporal sulcus $(r=0.85$, $P<0.000$ ). In the middle $\alpha 3 / \alpha 2$ group memory performance was related with the right precuneus cortex $(r=0.75, P=0.03)$ and superior temporal sulcus $(r=0.69$, $P<0.02$; Figure 4).

3. AVLT delayed recall: in the higher $\alpha 3 / \alpha 2$ group, a significant correlation was found with cortical thickness within the inferior parietal cortex bilaterally (left $r=0.86$,
$P<0.0000$; right $r=0.74, P=0.0005)$, left pericalcarine cortex $(r=0.76, P<0.0000)$, the banks of the superior temporal sulcus ( $r=0.81, P=0.0002)$, and right superior temporal cortex ( $r=0.73, P=0.001$; Figure 5).

\section{SPECT}

\section{Differences in cortical perfusion between groups}

Twenty-seven patients with MCI were selected for the present study and were considered at high risk (when the $\alpha 3 / \alpha 2$ EEG power ratio was $>1.17 ; \mathrm{N}=13$ ) or at low risk (when the $\alpha 3 / \alpha 2$ EEG power ratio was $<1.17 ; \mathrm{N}=14$ ) to develop AD. The two groups were comparable for age $(P=0.56)$, instruction in years $(P=0.87)$, sex $(P=0.17)$, ApoE genotype $(P=0.15)$, MMSE scores $(P=0.31)$, and WMH load ( $P=0.88$; Table 2$)$. Figure 6 demonstrates the visual rating of the SPECT images illustrative of healthy controls and MCI at low risk and at high risk to change over $\mathrm{AD}$. ANOVA results demonstrate that the chosen cutoff was compelling in distinguishing two different groups: patients with high risk to develop AD showed fundamentally higher $\alpha 3 / \alpha 2$ power ratio than patients with low risk $(P=0.0001)$. Indeed, in spite of the fact that the mean perfusion 

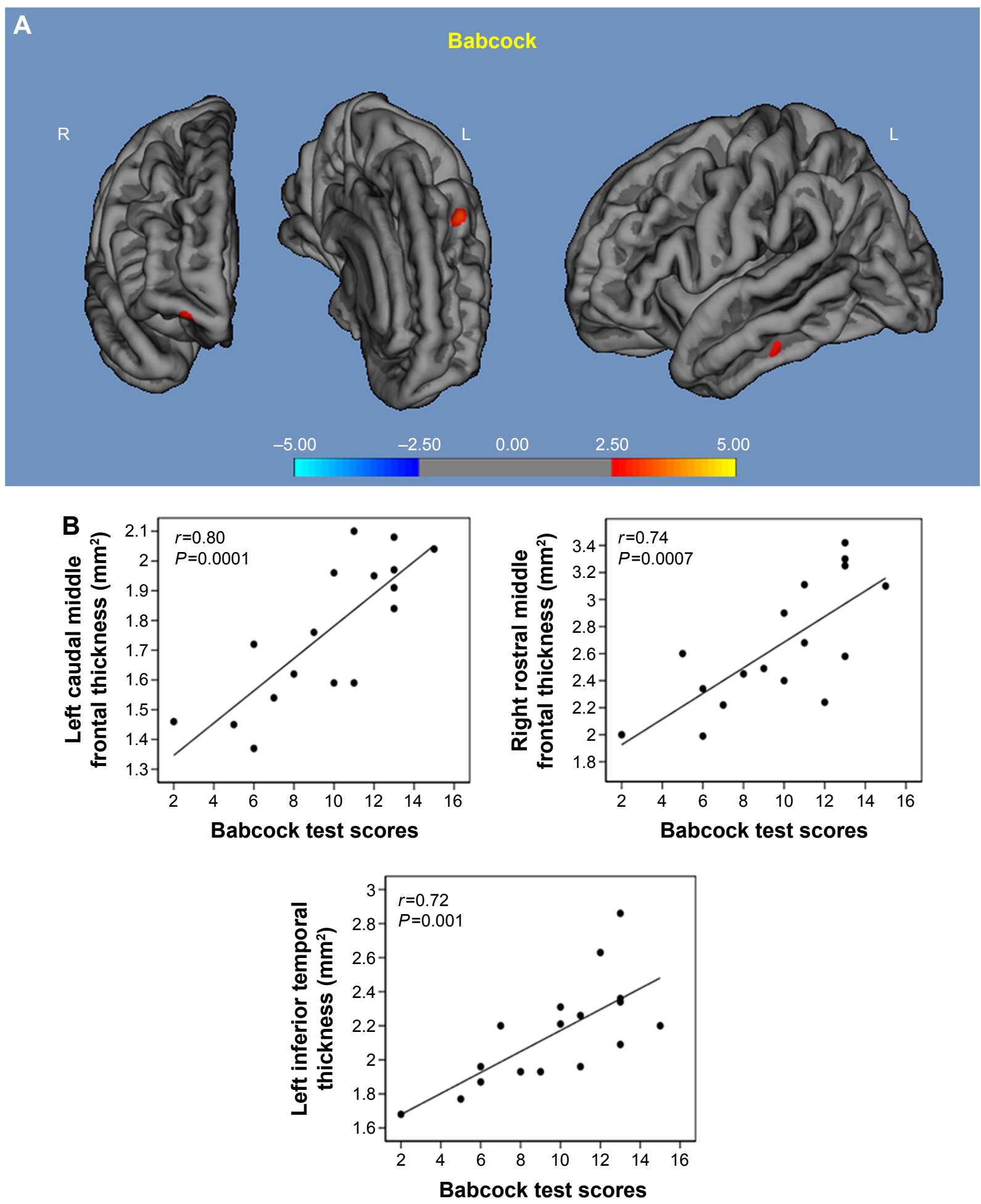

Figure 3 Correlation results between Babcock memory test $(\mathbf{A})$ and cortical thickness $(\mathbf{B})$.

Note: Red color represents the brain regions with higher regional cortical thickness.

in all the chosen brain regions was comparative between all the groups (all $P>0.38$ ), in the group with higher $\alpha 3 / \alpha 2$ power ratio, there was a trend toward a decreased perfusion $(P=0.06)$. Moreover, in patients with high risk compared with low risk for $\mathrm{AD}$, left hippocampal volumes were significantly reduced
( $P=0.001)$. Of note, no distinctions were found for theta, beta1, beta2, and gamma EEG power (all $P>0.11$ ).

In patients with high risk of developing $\mathrm{AD}$, a positive significant correlation was found between perfusion in the hippocampal area and theta oscillations $(r=0.729, P=0.005$; 

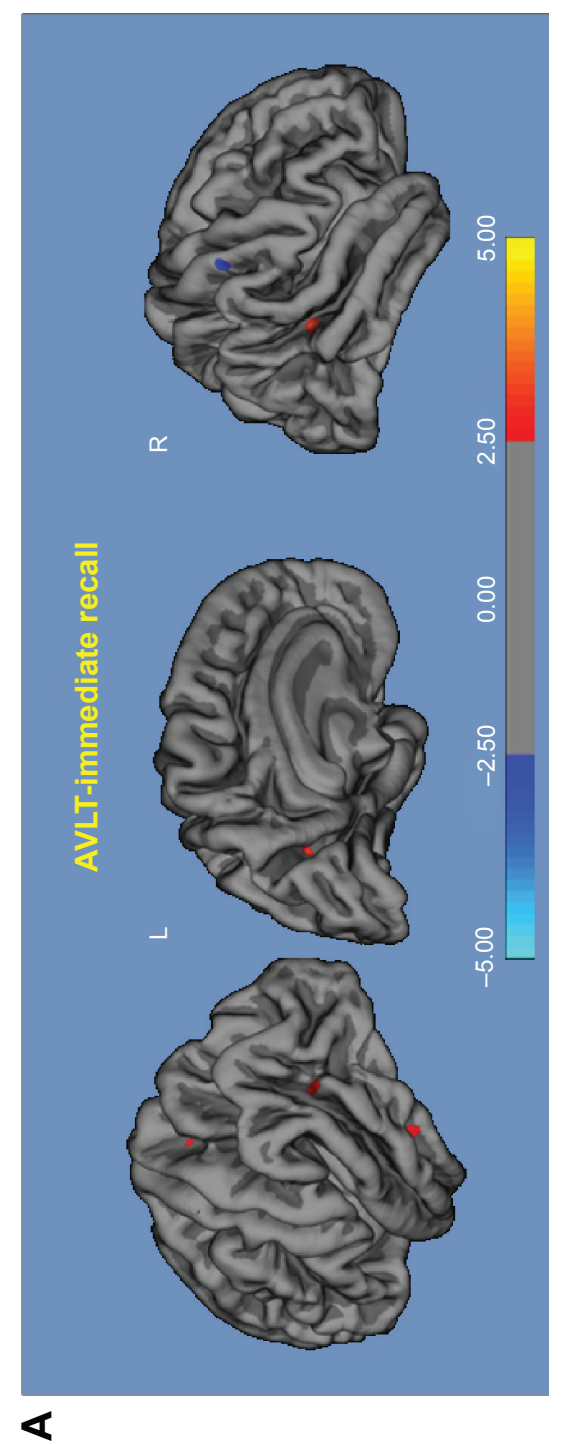

$\varangle$
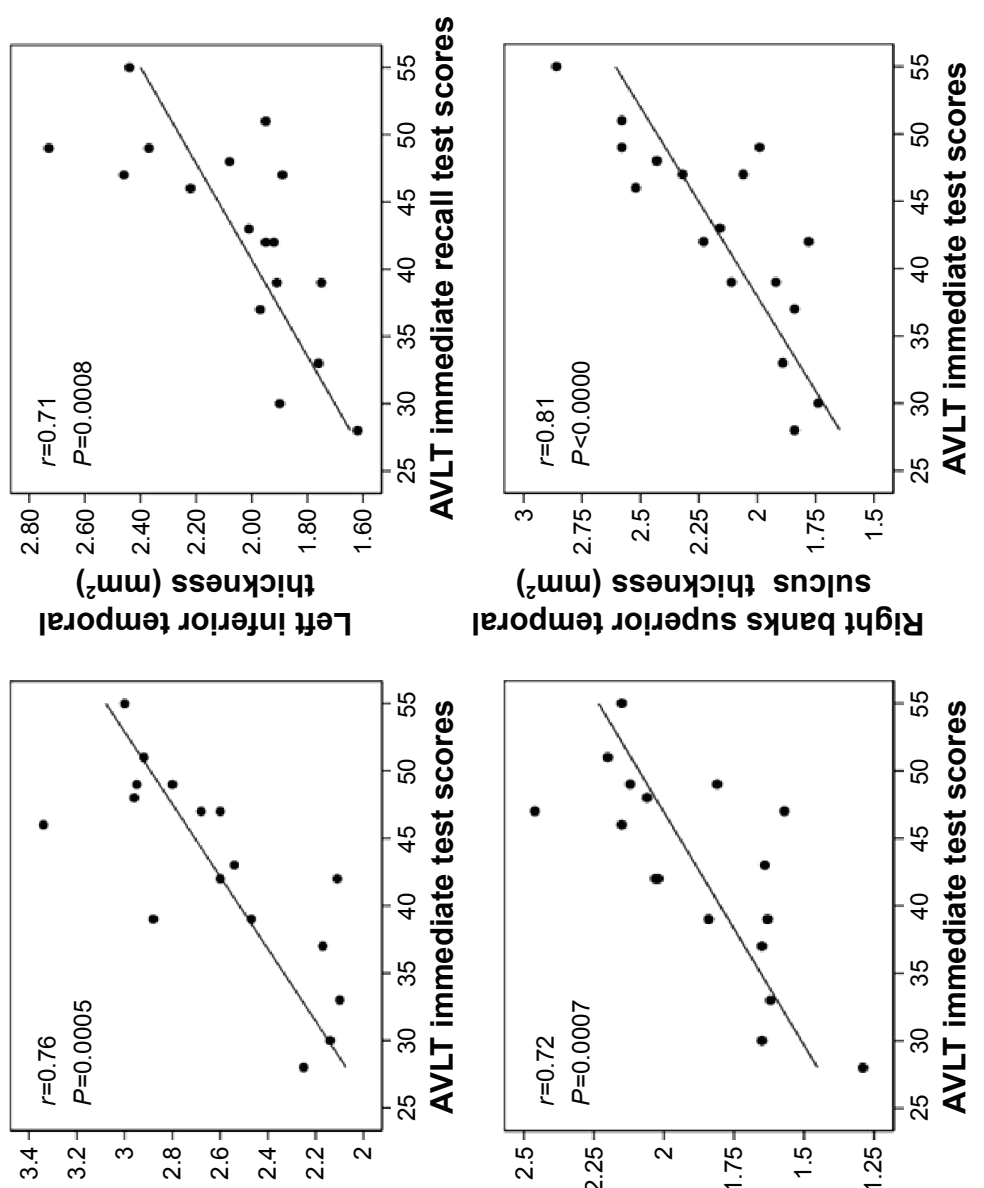

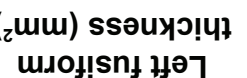

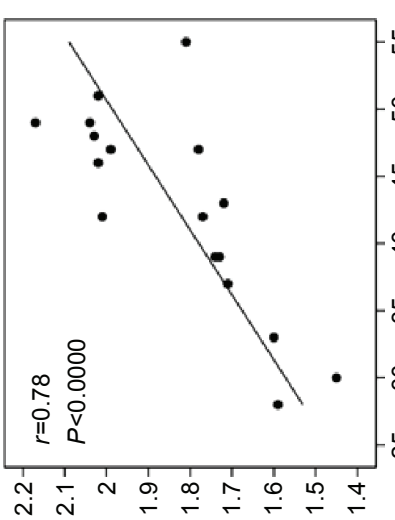

(zسu) ssəuप्रग!บ?

ก snəunวəגd భəา
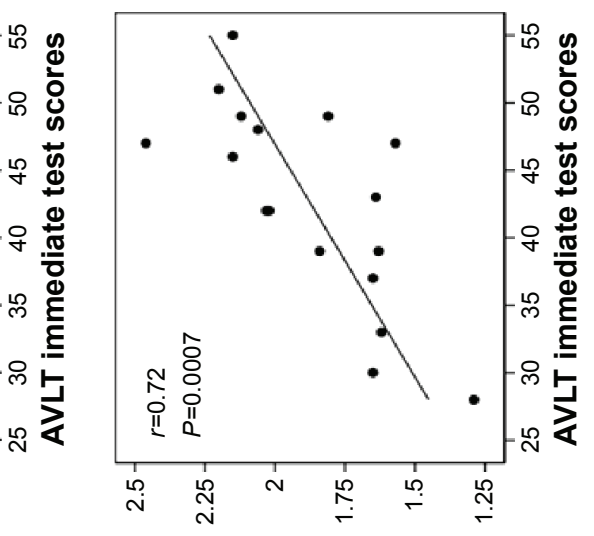

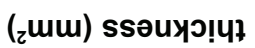

snəunכəəd ұ५6!

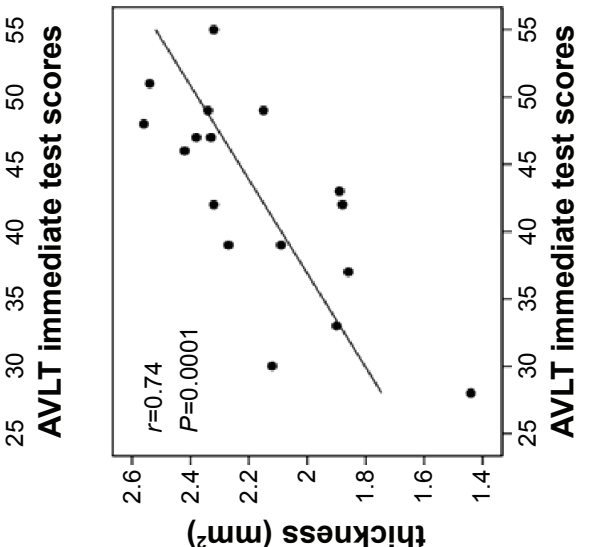

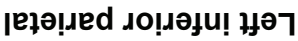



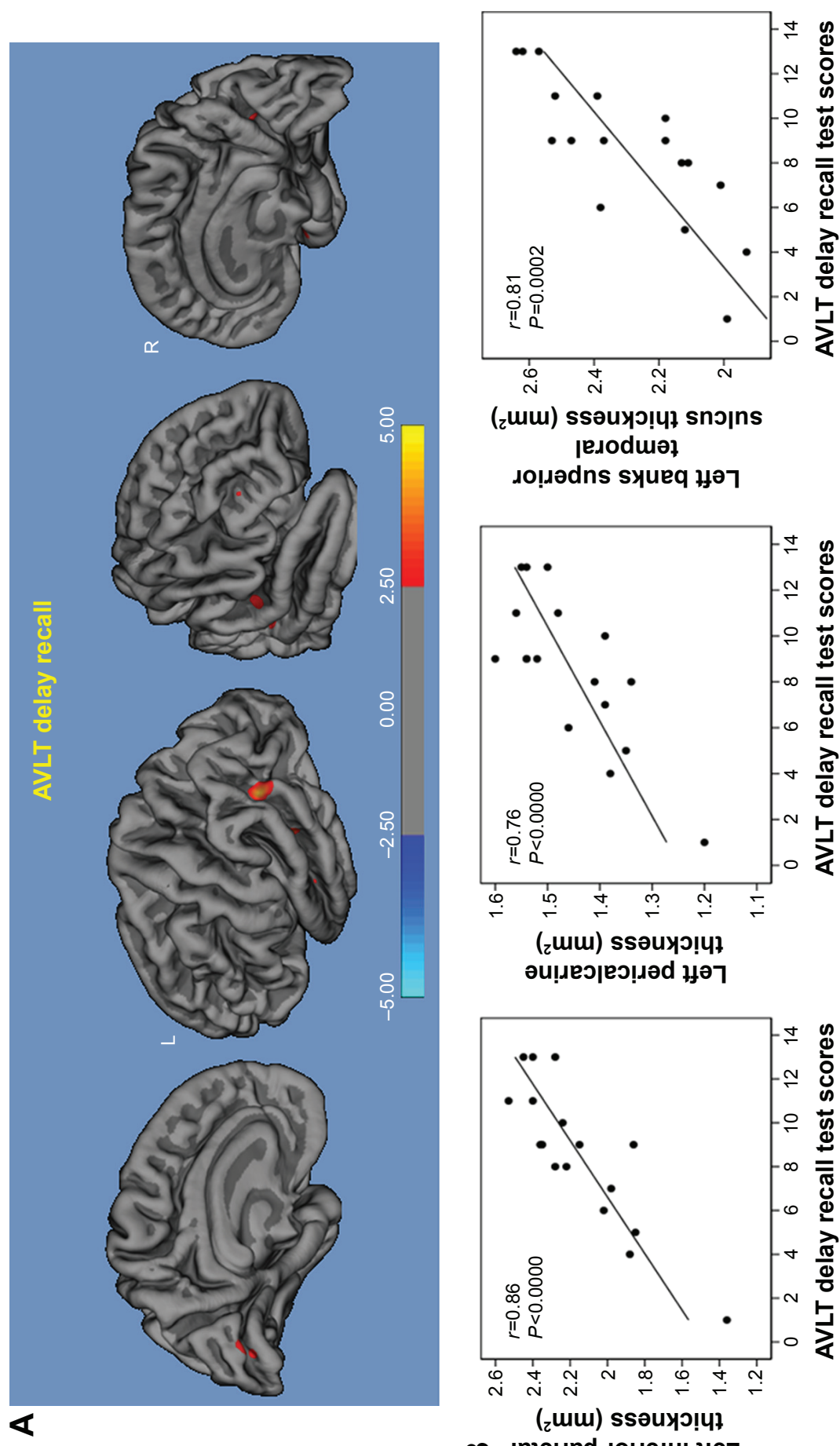

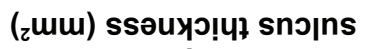

ןejoduə]

دo!ı⿰dns syueq ¥әา
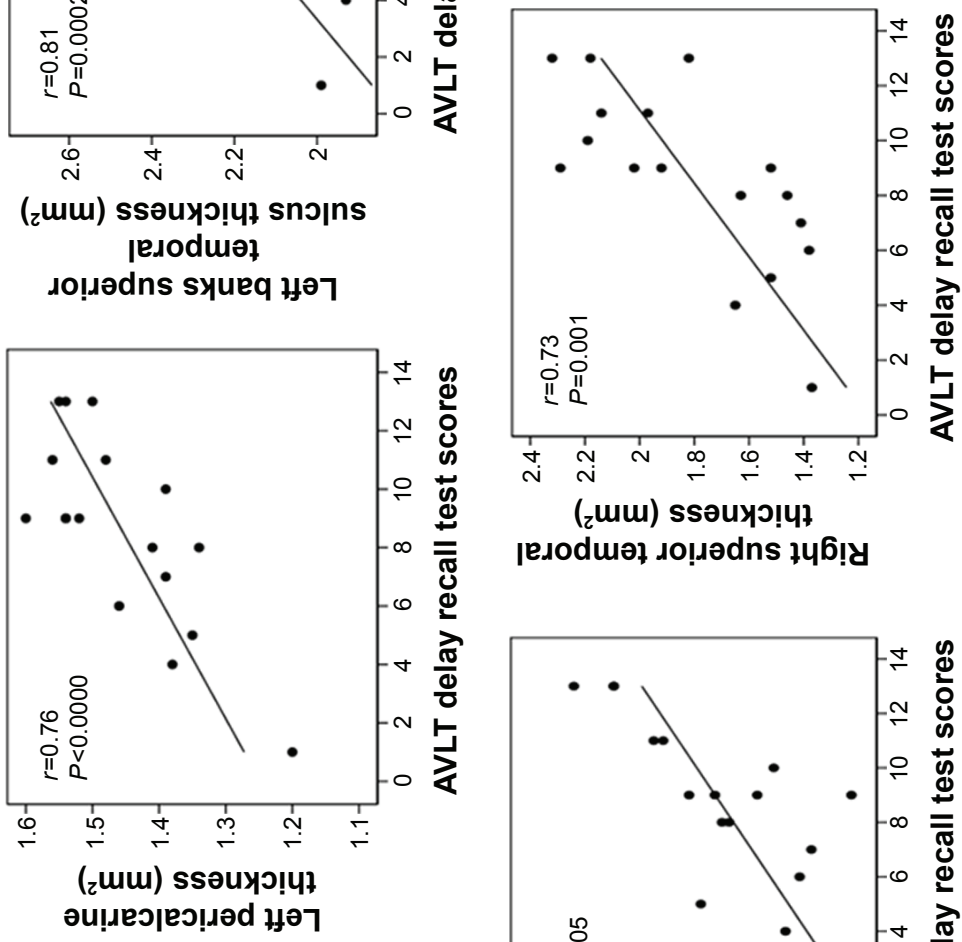

ןejoduə] до!ıәdns +46 !
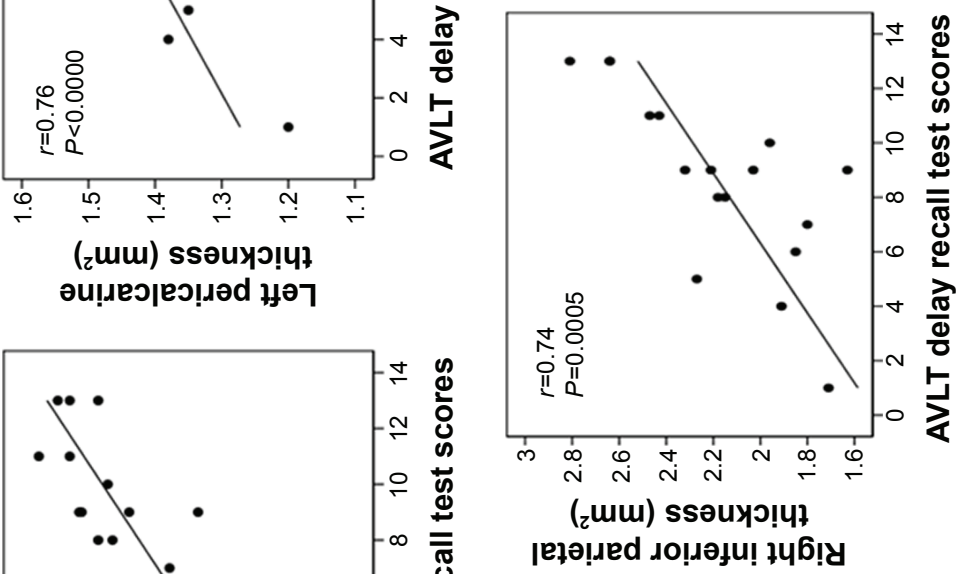

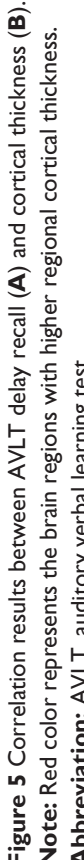


Table 2 Demographic and cognitive characteristics of the SPECT subjects' sample, disaggregated for increased levels of $\alpha 3 / \alpha 2$

\begin{tabular}{|c|c|c|c|}
\hline & At low-risk $\mathrm{MCl}$ & At high-risk $\mathrm{MCl}$ & $P$-value \\
\hline $\mathrm{N}$ & 14 & 13 & \\
\hline Age (years) (range) & $69.1 \pm 7.6(57-83)$ & $70.6 \pm 5.5(62-78)$ & 0.55 \\
\hline Sex (females) & $6(43 \%)$ & $9(69 \%)$ & 0.16 \\
\hline Education (years) (range) & $8.2 \pm 4.3(4-18)$ & $7.9 \pm 4.5(3-18)$ & 0.86 \\
\hline MMSE score (range) & $27.9 \pm 1.6(25-30)$ & $27.2 \pm 1.9(24-29)$ & 0.31 \\
\hline ApoE $\varepsilon 4$ genotype (carriers) & $2(29 \%)$ & $5(39 \%)$ & 0.15 \\
\hline Left hippocampal volume $\left(\mathrm{mm}^{3}\right)$ (range) & $2,606 \pm 353(1.92-3.01)$ & $2,073 \pm 4 \mid 2(I .23-2.64)$ & 0.001 \\
\hline Right hippocampal volume $\left(\mathrm{mm}^{3}\right)$ (range) & $2,58 I \pm 473(1.54-3.15)$ & $2,296 \pm 50 I(1.58-3.08)$ & 0.14 \\
\hline Wahlund total score (range) & $3.58 \pm 3.29(0.0-10.0)$ & $3.78 \pm 2.63(0.0-7.0)$ & 0.88 \\
\hline EEG theta frequency & $5.43 \pm 8.9 \mu \mathrm{V}^{2}$ & $6.0 \mathrm{I} \pm 5.4 \mu \mathrm{V}^{2}$ & 0.55 \\
\hline \multicolumn{4}{|l|}{ Memory } \\
\hline Babcock & $9.3 \pm 2.5$ & $9.7 \pm 3.1$ & 0.87 \\
\hline AVLT immediate recall & $40.7 \pm 3.7$ & $40.2 \pm 11.8$ & 0.48 \\
\hline AVLT delayed recall & $7.9 \pm 2.1$ & $8.1 \pm 2.4$ & 0.88 \\
\hline
\end{tabular}

Notes: Numbers denote mean \pm standard deviation and number (range). $P$ denotes significance on ANOVA.

Abbreviations: ANOVA, analysis of variance; AVLT, auditory verbal learning test; EEG, electroencephalogram; $\mathrm{MCl}$, mild cognitive impairment; MMSE, mini-mental state examination; SPECT, single-photon emission computed tomography.

Figure 7), whereas it was negative in the lower $\alpha 3 / \alpha 2 \mathrm{EEG}$ power ratio group. No significant correlations were discovered between hippocampus and theta rhythm in the whole group of patients $(r=0.086, P=0.671)$.

\section{Correlations between memory assessments and regional brain perfusion}

1. Babcock test: in the higher $\alpha 3 / \alpha 2 \mathrm{MCI}$ group, a noteworthy positive correlation was found with lowered perfusion values in precuneus bilaterally $(r=0.63, P=0.03)$ and superior temporal sulcus bilaterally ( $r=0.74, P=0.005)$. Additionally, a positive correlation was found with hippocampal decay $(r=0.75, P=0.001)$.

2. AVLT immediate recall: in the higher $\alpha 3 / \alpha 2 \mathrm{MCI}$ group, a correlation was found with decreased perfusion values in the caudal bank of the right temporal sulcus and middle frontal gyrus ( $r=0.75, P=0.003)$.

3. AVLT delayed recall: in the higher $\alpha 3 / \alpha 2 \mathrm{MCI}$ group, a correlation was found with decreased perfusion values in the inferior parietal lobule, in particular within the supramarginal gyrus $(r=0.09, P=0.05)$.

\section{Discussion}

\section{EEG and gray matter association}

In this study, the relationship between an EEG marker (the $\alpha 3 / \alpha 2$ proportion) and cortical thickness in patients with MCI was examined. The $\alpha 3 / \alpha 2$ proportion was chosen because previous evidence of our group has demonstrated that patients with MCI with larger $\alpha 3 / \alpha 2$ ratio are at major risk to develop AD. ${ }^{19-22}$ Our results show that the MCI

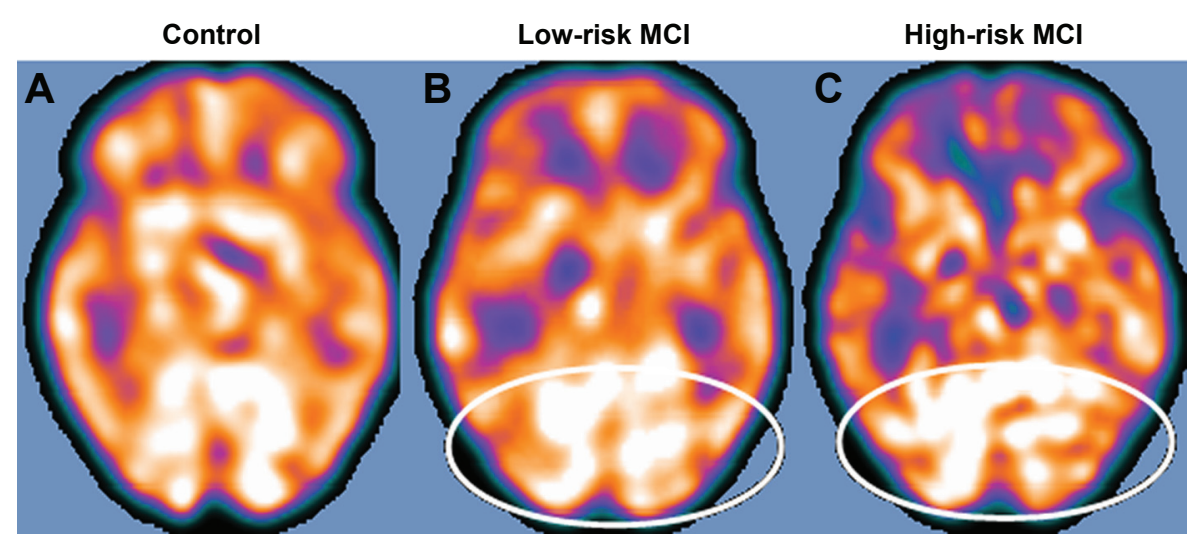

Figure 6 SPECT visual rating.

Notes: The output shows a SPECT visual inspection of glucose-uptake metabolism in one of the 17 controls (A), the white ovals denote areas of mild-to-moderate temporoparietal hypometabolism in one of the 14 patients with low-risk $\mathrm{MCl}(\mathbf{B})$ and in one of the 13 patients with high-risk $\mathrm{MCl}(\mathbf{C})$.

Abbreviations: $\mathrm{MCl}$, mild cognitive impairment; SPECT, single-photon emission computed tomography. 

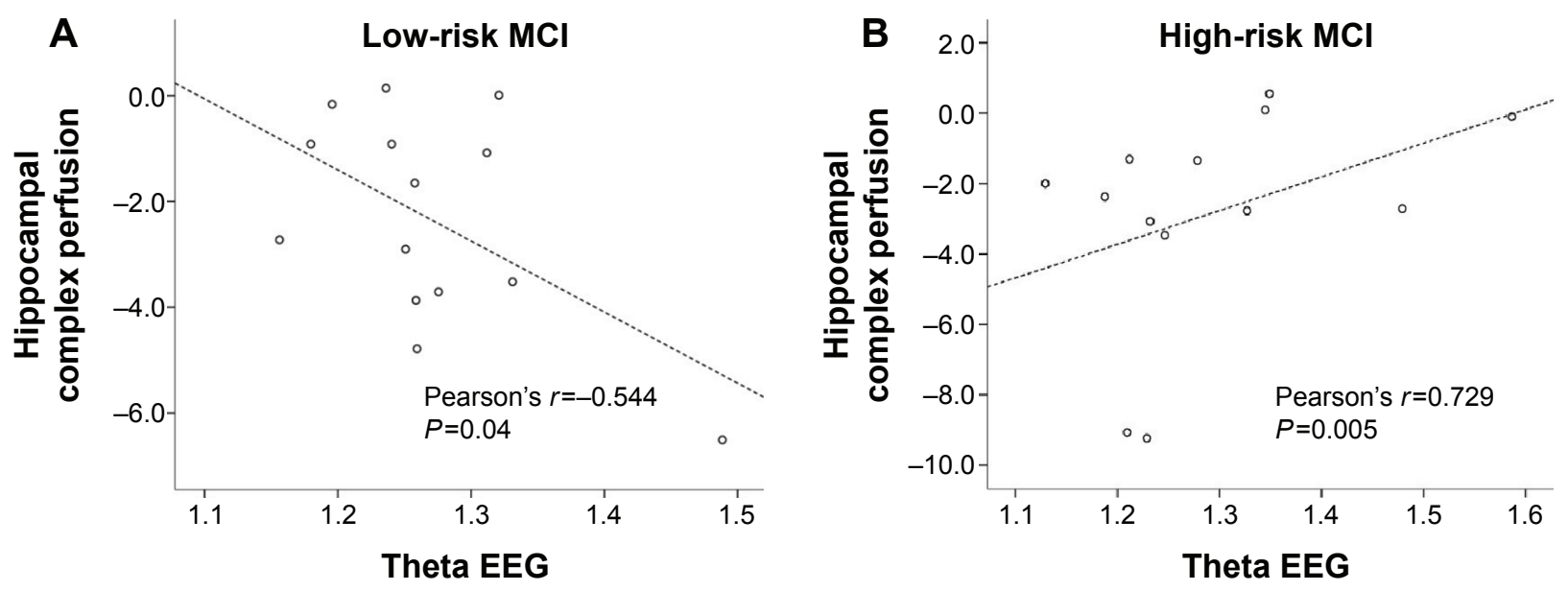

Figure 7 Pearson's $r$ correlations between EEG theta rhythm and hippocampal complex perfusion in patients at low risk (A) and at high risk (B) to develop AD. Abbreviations: $A D$, Alzheimer's disease; $E E G$, electroencephalogram; $\mathrm{MCl}$, mild cognitive impairment.

group with more significant $\alpha 3 / \alpha 2$ ratio is characterized by a greater cortical decay than low and middle $\alpha 3 / \alpha 2$ ratio groups, confirming earlier findings of our group..$^{32-46}$ Furthermore, greater decay is noticeable in two critical cerebral areas: the precuneus alongside the supramarginal gyrus (a cortical area having a place with the inferior parietal lobule) in the two hemispheres. ${ }^{47-55}$ Abnormal function and structure of the precuneus have been observed earlier in $\mathrm{MCI}^{55-59}$ and in addition in $\mathrm{AD},{ }^{60-64}$ so that the decay from the precuneus is recognized as a pathognomonic marker of early AD. Of note, the precuneus and the posterior cingulate, together with the medial temporal lobe, have been perceived as especially prone to amyloid deposition in $\mathrm{AD}$ neuropathology. ${ }^{65-68}$

\section{Association between EEG and perfusional changes}

Our results are consistent with previous logical examinations exhibiting that cognitively impaired individuals with huge plausibility to develop AD have decreased SPECT perfusion in both the temporoparietal cortex and inferior parietal lobule. ${ }^{55-59}$ Additionally, our results confirm perceived relationship with hippocampal decay. ${ }^{55}$ This study demonstrates a relationship between cerebral perfusion and theta rhythm. The connection develops while considering the groups independently. Patients with MCI who are at a diminished risk to develop $\mathrm{AD}$, demonstrating a pattern to higher cerebral regional blood perfusion, show a decreased power of theta EEG oscillations. In turn, in patients with MCI with higher risk to develop $\mathrm{AD}$, with a decreased cerebral blood perfusion, theta power has a tendency to become more prominent. The theta rhythm is thought to be made by the starting activity of the septal hippocampal loop. The hippocampus displays a depolarizing cholinergic-glutamatergic innervation starting all through the basal forebrain, the medial septum, and in addition the vertical limb in the diagonal band of Broca. The synchronized depolarization of hippocampal neurons generates potentials that have a frequency of 3-10 Hz normally distinguished as hippocampal theta rhythm. ${ }^{47,48}$ The loss of cholinergic innervation in AD, could provoke an excitotoxic glutamatergic activation. As a final consequence, the synaptic failure determined by the excitotoxic mechanisms give rise to an increase of theta oscillations.

A recent study, investigating the difference of fractional anisotropy from healthy controls to patients with MCI and mild $\mathrm{AD}$, found a correlation between the increasing damage of subcortical white matter and a progressive increase in EEG delta and theta spectral power together with a parallel widespread decrease in beta power. This correlation was stronger mainly in frontal areas ${ }^{69}$ This study proposed, as an alternative theory, that the increase in theta power could also be associated with the white matter damage, probably due to the global slowing of the nerve conduction speed provoked by the white matter fiber bundle disrupture, as proposed in previous research. ${ }^{16}$

\section{Neurophysiology and symptoms association}

Recent research has exhibited that during a powerful semantic encoding of new information, there is a desynchronization inside the temporoparietal memory-related networks. ${ }^{66}$ The association of synchronization with morphofunctional degeneration in AD has recently been portrayed by an intriguing study. ${ }^{67}$ The authors distinguished some hub districts (heteromodal associative regions) with particular vulnerability to $\mathrm{AD}$ pathology due to the destruction of 
inhibitory interneurons. In turn, the disinhibition determines a hypersynchronization of brain networks. Overall, this overactivity is excitotoxic and picks cell apoptosis and synaptic failure. Palop and Mucke stress the position of inhibitory interneuron brokenness inciting hypersynchronization. ${ }^{70-73}$ Our results are unsurprising with these first, thereby convincing investigative tests. Plausible integrative perspective of these different results might be as follows: 1) a more noteworthy neuronal activity inside the hub points begins from a brokenness of cell inhibition; 2) the subsequent dysinhibition drives the neural framework to an oversynchronization; 3) this oversynchronization is especially harmful in neural hub point inclined to amyloid weight; 4) these overactivated regions are liable to degeneration and decay; and 5) an achievable neurophsyiologic marker of this oversynchronization is the increase in the $\alpha 3 / \alpha 2$ proportion that we found inside these hub point regions. ${ }^{7-77}$ Interestingly, the atrophy of the precuneus is present together with disrupture in the supramarginal gyrus and, to the lesser degree, the inferior parietal cortex in the group of patients with MCI with a greater $\alpha 3 / \alpha 2$ power ratio. A late resting state $\mathrm{fMRI}$ study ${ }^{78}$ found that there is a specific pathway from the dorsal precuneus along with the supramarginal gyrus and parietal cortex. Thus, the MCI group with higher $\alpha 3 / \alpha 2$ power ratio could be assessed in light of the way that an entire network is weakened rather than detached cortical areas. ${ }^{79}$ In patients with MCI with lower or middle $\alpha 3 / \alpha 2$ EEG ratio, the cerebrovascular damage is in all probability a reason for brain damage, given the absence of a neurodegeneration marker.

\section{Brain memory association}

With an end goal to reject an arbitrary relationship among EEG markers and cortical decay, the proficiency on memory tests was explored. The memory tests were picked as a result of their regarded higher sensibility in patients with MCI who will convert to AD. ${ }^{1,9}$ Essentially, while assessing the memory execution in general, the groups are not different. This is likely an outcome of the MCI state in all MCI groups. Be that as it may, when concentrating on the relationship concerning memory general execution and a sensible fundamental marker, as to the cortical thickness, the MCI subgroup with the higher $\alpha 3 / \alpha 2 \mathrm{EEG}$ ratio, at significant risk to develop $\mathrm{AD}$, has shown an inverse correlation including memory test general execution and the cortical thickness. This outcome certifies that this is a different group of MCI exhibiting a clear specificity as for both the cortical atrophy and the compared memory execution. Similarly, no other sociodemographic or fundamental differentiations were found in the MCI groups that can explain the relationship assessment results. Of note, the cortical framework encompassing precuneus and inferior parietal cortex is significantly associated with visuospatial limits and left hippocampal disrupture. ${ }^{78-83}$ For a hypothetical explanation, we could speculate that the memory deficits are as a result of a weakened pathway for the semantic coding of the visuospatial abilities during the memory encoding. In this view, the failure of a discrete cerebral system (more than widespread specific measures) is more skilled in perceiving patients with MCI with prodromal AD.

\section{Network rearrangement in AD dementia}

The presence of a network disturbance in AD was affirmed by a recent study utilizing the diffusion-weighted imaging procedure. ${ }^{84}$ The existence of a network disruption in AD was confirmed by a recent study using the diffusion-weighted imaging technique. ${ }^{84}$ The authors demonstrated a failure of structural connectivity increasing from the MCI to mild and moderate AD states, centered on entorhinal cortex and hippocampus and propagating to the neighborhood regions. Encoding memory states have been convincingly related to the higher alpha band $(10-13 \mathrm{~Hz}) \cdot{ }^{84,85}$ EEG and magnetoencephalography studies demonstrated that a correct memory performance, both of those in encoding and in recovery, requires desynchronization (or power decrease) in higher alpha oscillations. ${ }^{24,86-91}$ The synchronization (or power increase) of EEG alpha force has been related to a lack of data transmission. ${ }^{27,92,93}$ This theory has been asserted in an investigative study in patients with memory deficiencies ${ }^{94-96}$ and also through states where no mental handling (eg, slow wave sleep or epileptic seizures) has been found. ${ }^{78,97,98}$ Concerning cognitive failure typical of $\mathrm{AD}$, the synaptic disrupture could sustain the physiological adaptability of neural networks, hindering the tuning of mental function through the desynchronizing mechanisms. Consequently, it may be conjectured that the impairment from the cortical networks in light of degenerative issue, actuating cortical atrophy, could take an oversynchronization of the brain rhythm activity. The encoding of a semantic data code could be harmed by the oversynchronization state on the higher EEG alpha power avoiding the transformation and the retrieval of episodic memory. ${ }^{99-102}$ Of note, the discovery and assessment of a semantic cue are important in the new diagnostic criteria for AD. ${ }^{103-127}$

\section{Study limitations}

There are some limitations due to the obvious explorative nature of this study: 1) further studies are needed to confirm our result, using larger samples and applying an appropriate 
multiple comparison correction; 2) the pattern of cortical thickness should be investigated on the remaining EEG frequency measures; 3 ) the retrospective nature of the study prevented a direct assessment of whether patients with increase in $\alpha 3 / \alpha 2$ EEG power ratio will convert to $\mathrm{AD}$ or other neurodegenerative diseases; and 4) the conservative $P<0.001$ used here is not necessarily sufficient, given the number of comparisons. Regardless, given the explorative nature of the study, it is plausible for a permissive approach in order to avoid possibly rejecting the interesting results. It remains clear that further studies with less permissive statistical approach are mandatory to confirm the results.

\section{Conclusion}

Increase in EEG $\alpha 3 / \alpha 2$ synchronization was associated with brain atrophy and lessened blood regional perfusion in the visuospatial associative hub brain regions. In addition, lessened local regional perfusion and cortical decay are extensively correlated with memory loss in patients with MCI. This EEG biomarker could be helpful for early AD dementia diagnosis and monitoring clinical therapeutic trials.

\section{Disclosure}

The author reports no conflicts of interest in this work.

\section{References}

1. Dubois B, Feldman HH, Jacova C, et al. Research criteria for the diagnosis of Alzheimer's disease: revising the NINCDS-ADRDA criteria. Lancet Neurol. 2007;6(8):734-746.

2. Albert MS, DeKosky ST, Dickson D, et al. The diagnosis of mild cognitive impairment due to Alzheimer's disease: recommendations from the National Institute on Aging-Alzheimer's Association workgroups on diagnostic guidelines for Alzheimer's disease. Alzheimers Dement 2011;7(3):270-279.

3. Hampel H, Burger K, Teipel SJ, et al. Core candidate neurochemical and imaging biomarkers of Alzheimer's disease. Alzheimers Dement. 2008;4(1):38-48.

4. Galluzzi S, Geroldi C, Amicucci G, et al; Translational Outpatient Memory Clinic Working Group. Supporting evidence for using biomarkers in the diagnosis of MCI due to AD. J Neurol. 2013;260(2):640-650.

5. Frisoni GB, Sabattoli F, Lee AD, Dutton RA, Toga AW, Thompson PM. In vivo neuropathology of the hippocampal formation in $\mathrm{AD}$ : a radial mapping MR-based study. Neuroimage. 2006;32(1):104-110.

6. Frisoni GB, Pievani M, Testa C, et al. The topography of grey matter involvement in early and late onset Alzheimer's disease. Brain. 2007; 130(pt 3):720-730.

7. Frisoni GB, Ganzola R, Canu E, et al. Mapping local hippocampal changes in Alzheimer's disease and normal ageing with MRI at 3 Tesla. Brain. 2008;131(pt 12):3266-3276.

8. Frisoni GB, Prestia A, Rasser PE, Bonetti M, Thompson PM. In vivo mapping of incremental cortical atrophy from incipient to overt Alzheimer's disease. J Neurol. 2009;256(6):916-924.

9. Frisoni GB. Alzheimer disease: biomarker trajectories across stages of Alzheimer disease. Nat Rev Neurol. 2012;8(6):299-300.

10. van Strien NM, Cappaert NL, Witter MP. The anatomy of memory: an interactive overview of the parahippocampal-hippocampal network. Nat Rev Neurosci. 2009;10(4):272-282.
11. Missonnier P, Herrmann FR, Michon A, Fazio-Costa L, Gold G, Giannakopoulos P. Early disturbances of gamma band dynamics in mild cognitive impairment. J Neural Transm. 2010;117(4):489-498.

12. Steriade M. Grouping of brain rhythms in corticothalamic systems. Neuroscience. 2006;137(4):1087-1106.

13. Lopes da Silva FH, Vos JE, Mooibroek J, van Rotterdam A. Relative contributions of intracortical and thalamo-cortical processes in the generation of alpha rhythms, revealed by partial coherence analysis. Electroencephalogr Clin Neurophysiol. 1980;50(5-6):449-456.

14. Ingber L, Nunez PL. Neocortical dynamics at multiple scales: EEG standing waves, statistical mechanics, and physical analogs. Math Biosci. 2011;229(2):160-173.

15. Moretti DV, Babiloni F, Carducci F, et al. Computerized processing of EEG-EOG-EMG artifacts for multicentric studies in EEG oscillations and event-related potentials. Int J Pshycophysiol. 2003;47(3):199-216.

16. Moretti DV, Miniussi C, Frisoni G, et al. Vascular damage and EEG markers in subjects with mild cognitive impairment. Neurophysiol Clin. 2007;118:1866-1876.

17. Moretti DV, Miniussi C, Frisoni GB, et al. Hippocampal atrophy and EEG markers in subjects with mild cognitive impairment. Clin Neurophysiol. 2007;118(12):2716-2729.

18. Moretti DV, Frisoni GB, Pievani M, et al. Cerebrovascular disease and hippocampal atrophy are differently linked to functional coupling of brain areas: an EEG coherence study in MCI subjects. J Alzheimers Dis. 2008;14(3):285-299.

19. Moretti DV, Frisoni GB, Pievani M, et al. Brain vascular damage of cholinergic pathways and E.E.G. markers in mild cognitive impairment 2008. J Alzheimers Dis. 2008;15(3):357-372.

20. Moretti DV. Electroencephalography reveals lower regional blood perfusion and atrophy of the temporoparietal network associated with memory deficits and hippocampal volume reduction in mild cognitive impairment due to Alzheimer's disease. Neuropsychiatr Dis Treat. 2015;11:461-470.

21. Moretti DV. Theta and alpha EEG frequency interplay in subjects with mild cognitive impairment: Evidence from EEG, MRI and SPECT brain modifications. Front Aging Neurosci. 2015;7:31.

22. Vito Moretti D. Understanding early dementia: EEG, MRI, SPECT and memory evaluation. Trans Neurosci. 2015;6(1):32-46.

23. Klimesch W. Evoked alpha and early access to the knowledge system: the P1 inhibition timing hypothesis. Brain Res. 2011;1408:52-71. Review.

24. Shannon CE, Weaver W. The Mathematical Theory of Communication. Urbana, IL: University of Illinois Press; 1949.

25. Folstein MF, Folstein SE, McHugh PR. Mini mental state': a practical method for grading the cognitive state of patients for clinician. J Psychiatr Res. 1975;12(3):189-198.

26. Hughes CP, Berg L, Danziger WL, Cohen LA, Martin RL. A new clinical rating scale for the staging of dementia. Br J Psychiatry. 1982;140: $1225-1230$.

27. Rosen WG, Terry RD, Fuld PA, Katzman R, Peck A. Pathological verification of ischemic score in differentiation of dementias. Ann Neurol. 1980;7(5):486-488.

28. Lawton MP, Brodie EM. Assessment of older people: self maintaining and instrumental activity of daily living. J Gerontol. 1969;9(3):179-186.

29. Lezak M, Howieson D, Loring DW. Neuropsychological Assessment. 4th ed. Oxford: University Press; 2004.

30. Radloff LS. The CES-D scale: a self-report depression scale for research in the general population. Appl Psychol Meas. 1977;1:385-401.

31. Caroli A, Testa C, Geroldi C, et al. Brain perfusion correlates of medial temporal lobe atrophy and white matter hyperintensities in mild cognitive impairment. J Neurol. 2007;254(8):1000-1008.

32. Portet F, Ousset PJ, Visser PJ, et al; MCI Working Group of the European Consortium on Alzheimer's Disease (EADC). Mild cognitive impairment (MCI) in medical practice: a critical review of the concept and new diagnostic procedure. Report of the MCI Working Group of the European Consortium on Alzheimer's Disease. J Neurol Neurosurg Psychiatry. 2006;77(6):714-718. 
33. Moretti DV. Involvement of mirror neuron system in prodromal Alzheimer's disease. BBA Clin. 2016;15(5):46-53.

34. Klimesch W. EEG-alpha rhythms and memory processes. Int J Psychophysiol. 1997;26(1-3):319-340.

35. Klimesch W. EEG alpha and theta oscillations reflect cognitive and memory performance: a review and analysis. Brain Res Rev. 1999;29(2-3): 169-195.

36. Kaplan AY. The problem of segmental description of human electroencephalogram. Hum Physiol. 1999;25:107-114.

37. Cohen BA, Sances A. Stationarity of the human electroencephalogram. Med Biol Eng Comput. 1977;15:513-518.

38. Kawabata N. Test of statistical stability of the electroencephalogram. Biol Cybern. 1976;22:235-238.

39. McEwen JA, Anderson GB. Modeling the stationarity and gaussianity of spontaneous electroencephalographic activity. IEEE Trans Biomed Eng. 1975;22:361-369.

40. Kipiński L, König R, Sielużycki C, Kordecki W. Application of modern tests for stationarity to single-trial MEG data: transferring powerful statistical tools from econometrics to neuroscience. Biol Cybern. 2011; 105(3-4):183-195.

41. Moretti DV, Fracassi C, Pievani M, et al. Increase of theta/gamma ratio is associated with memory impairment. Clin Neurophysiol. 2009; 120(2):295-303.

42. Moretti DV, Pievani M, Fracassi C, et al. Increase of theta/gamma and $\alpha 3 / \alpha 2$ ratio is associated with amygdalo-hippocampal complex atrophy. J Alzheimers Dis. 2009;17(2):349-357.

43. Moretti DV, Pievani M, Geroldi C, et al. Increasing of hippocampal atrophy and cerebrovascular damage is differently associated with functional cortical coupling in MCI patients. Alzheimer Dis Assoc Disord. 2009;23(4):323-332.

44. Cabeza R. Hemispheric asymmetry reduction in older adults: the HAROLD model. Psychol Aging. 2002;17(1):85-100. Review.

45. Balsters JH, O'Connell RG, Galli A, et al. Changes in resting connectivity with age: a simultaneous electroencephalogram and functional magnetic resonance imaging investigation. Neurobiol Aging. 2013; 34(9):2194-2207.

46. Watson P, Conroy A, Moran G, Duncan S. Retrospective study of sensitivity and specificity of EEG in the elderly compared with younger age groups. Epilepsy Behav. 2012;25(3):408-411.

47. Tenke CE, Kayser J, Miller L, et al. Neuronal generators of posterior EEG alpha reflect individual differences in prioritizing personal spirituality. Biol Psychol. 2013;94(2):426-432.

48. Grandy TH, Werkle-Bergner M, Chicherio C, Schmiedek F, Lövdén M, Lindenberger U. Peak individual alpha frequency qualifies as a stable neurophysiological trait marker in healthy younger and older adults. Psychophysiology. 2013;50(6):570-582.

49. Grandy TH, Werkle-Bergner M, Chicherio C, Lövdén M, Schmiedek F, Lindenberger U. Individual alpha peak frequency is related to latent factors of general cognitive abilities. Neuroimage. 2013;79: $10-18$.

50. Bekhtereva V, Sander C, Forschack N, Olbrich S, Hegerl U, Müller MM. Effects of EEG-vigilance regulation patterns on early perceptual processes in human visual cortex. Clin Neurophysiol. 2014;125(1): 98-107.

51. Ségonne F, Dale AM, Busa E, et al. A hybrid approach to the skull stripping problem in MRI. Neuroimage. 2004;22(3):1060-1075.

52. Fischl B, Dale AM. Measuring the thickness of the human cerebral cortex using magnetic resonance images. Proc Natl Acad Sci US A. 2000; 97(20):11044-11049.

53. Han X, Jovicich J, Salat D, et al. Reliability of MRI-derived measurements of human cerebral cortical thickness: the effects of field strength, scanner upgrade and manufacturer. Neuroimage. 2006;32(1): 180-194.

54. Gronenschild EH, Habets P, Jacobs HI, et al. The effects of FreeSurfer version, workstation type, and Macintosh operating system version on anatomical volume and cortical thickness measurements. PLoS One. 2012;7(6):e38234.
55. DeCarli C, Fletcher E, Ramey V, Harvey D, Jagust WJ. Anatomical mapping of white matter hyperintensities (WMH): exploring the relationships between periventricular WMH, deep WMH, and total WMH burden. Stroke. 2005;36(1):50-55.

56. Pennanen C, Testa C, Laasko MP, et al. A voxel based morphometry study on mild cognitive impairment. J Neurol Neurosurg Psychiatry. 2005;76(1):11-14.

57. Markesbery WR, Schmitt RA, Kryscio RJ, Davis D, Smith C, Wekstein D. Neuropathologic substrate of mild cognitive impairment. Arch Neurol. 2006;63(1):38-46.

58. McKhann GM, Knopman DS, Chertkow H, et al. The diagnosis of dementia due to Alzheimer's disease: recommendations from the national institute on aging-Alzheimer's association workgroups on diagnostic guidelines for Alzheimer's disease. Alzheimers Dement. 2011;7(3):263-269.

59. Sperling RA, Aisen PS, Beckett LA, et al. Toward defining the preclinical stages of Alzheimer's disease: recommendations from the National Institute on Aging-Alzheimer's Association workgroups on diagnostic guidelines for Alzheimer's disease. Alzheimers Dement. 2011;7(3):280-292.

60. Petersen RC, Doody R, Kurz A, et al. Current concepts in mild cognitive impairment. Arch Neurol. 2001;58(12):1985-1992.

61. Matsuda $\mathrm{H}$. The role of neuroimaging in mild cognitive impairment. Neuropathology. 2007;27(6):570-577.

62. Petrella JR, Wang L, Krishnan S, et al. Cortical deactivation in mild cognitive impairment: high-field-strength functional MR imaging. Radiology. 2007;245(1):224-235.

63. Pihlajamaki M, Jauhiainen AM, Soininen H. Structural and functional MRI in mild cognitive impairment. Curr Alzheimer Res. 2009;6(2): 179-185.

64. Dickerson BC, Sperling RA. Large-scale functional brain network abnormalities in Alzheimer's disease: insights from functional neuroimaging. Behav Neurol. 2009;21(1):63-75.

65. Ryu SY, Kwon MJ, Lee SB, et al. Measurement of precuneal and hippocampal volumes using magnetic resonance volumetry in Alzheimer's disease. J Clin Neurol. 2010;6(4):196-203.

66. Sperling RA, Dickerson BC, Pihlajamaki M, et al. Functional alterations in memory networks in early Alzheimer's disease. Neuromolecular Med. 2010;12(1):27-43.

67. Palop JJ, Mucke L. Synaptic depression and aberrant excitatory network activity in Alzheimer's disease: two faces of the same coin? Neuromolecular Med. 2010;12(1):48-55.

68. Pievani M, de Haan W, Wu T, Seeley WW, Frisoni GB. Functional network disruption in the degenerative dementias. Lancet Neurol. 2011; 10(9):829-843.

69. Scrascia F, Curcio G, Ursini F, et al. Relationship among diffusion tensor imaging, EEG activity, and cognitive status in mild cognitive impairment and Alzheimer's disease patients. J Alzheimers Dis. 2014; 38(4):939-950.

70. Bhattacharya BS, Coyle D, Maguire LP. Alpha and theta rhythm abnormality in Alzheimer's disease: a study using a computational model. Adv Exp Med Biol. 2011;718:57-73.

71. Rossini PM, Buscema M, Capriotti M, et al. Is it possible to automatically distinguish resting EEG data of normal elderly vs. mild cognitive impairment subjects with high degree of accuracy? Clin Neurophysiol. 2008;119(7):1534-1545.

72. Wu X, Li R, Fleisher AS, et al. Altered default mode network connectivity in Alzheimer's disease - a resting functional MRI and Bayesian network study. Hum Brain Mapp. 2011;32(11):1868-1881.

73. Wonderlick JS, Ziegler DA, Hosseini-Varnamkhasti P, et al. Reliability of MRI-derived cortical and subcortical morphometric measures: effects of pulse sequence, voxel geometry, and parallel imaging. Neuroimage. 2009;44(4):1324-1333.

74. Jones DT, Machulda MM, Vemuri P, et al. Age-related changes in the default mode network are more advanced in Alzheimer disease. Neurology. 2011;77(16):1524-1531.

75. Brier MR, Thomas JB, Snyder AZ, et al. Loss of intranetwork and internetwork resting state functional connections with Alzheimer's disease progression. J Neurosci. 2012;32(26):8890-8899. 
76. de Haan W, Mott K, van Straaten EC, Scheltens P, Stam CJ. Activity dependent degeneration explains hub vulnerability in Alzheimer's disease. PLoS Comput Biol. 2012;8(8):e1002582.

77. Stam CJ, van der Made Y, Pijnenburg YA, Scheltens P. EEG synchronization in mild cognitive impairment and Alzheimer's disease. Acta Neurol Scand. 2003;108(2):90-96.

78. Zhang S, Li CS. Functional connectivity mapping of the human precuneus by resting state fMRI. Neuroimage. 2012;59(4):3548-3562.

79. Morbelli S, Drzezga A, Perneczky R, et al. Resting metabolic connectivity in prodromal Alzheimer's disease. A European Alzheimer Disease Consortium (EADC) project. Neurobiol Aging. 2012;33(11): 2533-2550.

80. Ghaem O, Mellet E, Crivello F, et al. Mental navigation along memorized routes activates the hippocampus, precuneus, and insula. Neuroreport. 1997;8(3):739-744.

81. Leichnetz GR. Connections of the medial posterior parietal cortex (area 7m) in the monkey. Anat Rec. 2001;263(2):215-236.

82. Cavanna AE, Trimble MR. The precuneus: a review of its functional anatomy and behavioural correlates. Brain. 2006;129(pt 3):564-583.

83. Wenderoth N, Debaere F, Sunaert S, Swinnen SP. The role of anterior cingulate cortex and precuneus in the coordination of motor behaviour. Eur J Neurosci. 2005;22(1):235-246.

84. Mallio CA, Schmidt R, de Reus MA, et al. Epicentral disruption of structural connectivity in Alzheimer's disease. CNS Neurosci Ther. 2015; 21(10):837-845.

85. Klimesch W, Doppelmayr M, Stadler W, Pöllhuber D, Sauseng P, Röhm D. Episodic retrieval is reflected by a process specific increase in human electroencephalographic theta activity. Neurosci Lett. 2001 302(1):49-52.

86. Fries P, Reynolds JH, Rorie AE, Desimone R. Modulation of oscillatory neuronal synchronization by selective visual attention. Science. 2001;291(5508):1560-1563.

87. Kilner JM, Mattout J, Henson R, Friston KJ. Hemodynamic correlates of EEG: a heuristic. Neuroimage. 2005;28(1):280-286.

88. Wyart V, Tallon-Baudry C. Neural dissociation between visual awareness and spatial attention. $J$ Neurosci. 2008;28(10):2667-2679.

89. Spitzer B, Hanslmayr S, Opitz B, Mecklinger A, Bäuml K-H. Oscillatory correlates of retrieval-induced forgetting in recognition memory. J Cogn Neurosci. 2009;21(5):976-990.

90. Staudigl T, Hanslmayr S, Bäuml K-HT. Thetao scillations reflect the dynamics of interference in episodic memory retrieval. J Neurosci. 2010;30(34):11356-11362.

91. Hanslmayr S, Staudigl T, Aslan A, Bäuml K-H. Theta oscillations predict the detrimental effects of memory retrieval. Cogn Affect Behav Neurosci. 2010;10(3):329-338.

92. Hanslmayr S, Staudigl T, Fellner MC. Oscillatory power decreases and long-term memory: the information via desynchronization hypothesis. Front Hum Neurosci. 2012;6:74.

93. Jensen O, Mazaheri A. Shaping functional architecture by oscillatory alpha activity: gating by inhibition. Front Hum Neurosci. 2010;4:186.

94. Norman KA. How hippocampus and cortex contribute to recognition memory: revisiting the complementary learning systems model. Hippocampus. 2010;20(11):1217-1227.

95. Schneidman E, Puchalla JL, Segev R, Harris RA, Bialek W, Berry MJ. Synergy from silence in a combinatorial neural code. JNeurosci. 2011; 31(44):15732-15741.

96. Kurimoto R, Ishii R, Canuet L, et al. Induced oscillatory responses during the Sternberg's visual memory task in patients with Alzheimer's disease and mild cognitive impairment. Neuroimage. 2012;59(4):4132-4140.

97. Goard M, Dan Y. Basal forebrain activation enhances cortical coding of natural scenes. Nat Neurosci. 2009;12(11):1444-1449.

98. Chalk M, Herrero JL, Gieselmann MA, Delicato LS, Gotthardt S, Thiele A. Attention reduces stimulus-driven gamma frequency oscillations and spike field coherence in V1. Neuron. 2010;66(1):114-125.

99. Barlow HB. The coding of sensory messages. In: Thorpe WH, Zangwill OL, editors. Current Problems in Animal Behaviour. Cambridge: Cambridge University Press; 1961:331-360.
100. Bialek W, Rieke F, de Ruytervan Steveninck RR, Warland D. Reading a neural code. Science. 1991;252(5014):1854-1857.

101. Hanslmayr S, Spitzer B, Bäuml K-H. Brain oscillations dissociate between semantic and non semantic encoding of episodic memories. Cereb Cortex. 2009;19(7):1631-1640.

102. Craik FIM. Levels of processing: past, present and future? Memory. 2002;10(5-6):305-318.

103. Moretti DV, Pievani M, Geroldi C, et al. EEG markers discriminate among different subgroup of patients with mild cognitive impairment. Am J Alzheimers Dis Other Demen. 2010;25(1):58-73.

104. Moretti DV, Frisoni GB, Fracassi C, et al. MCI patients' EEGs show group differences between those who progress and those who do not progress to AD. Neurobiol Aging. 2011;32(4):563-571.

105. Moretti DV, Frisoni GB, Binetti G, Zanetti O. Anatomical substrate and scalp EEG markers are correlated in subjects with cognitive impairment and Alzheimer's disease. Front Psychiatr. 2011;1:152.

106. Moretti DV, Prestia A, Fracassi C, et al. Volumetric differences in mapped hippocampal regions correlate with increase of high alpha rhythm in Alzheimer's disease. Int J Alzheimers Dis. 2011;2011: 208-218.

107. Moretti DV, Paternicò D, Binetti G, Zanetti O, Frisoni GB. EEG markers are associated to gray matter changes in thalamus and basal ganglia in subjects with mild cognitive impairment. Neuroimage. 2012;60(1):489-496

108. Moretti DV, Prestia A, Fracassi C, Binetti G, Zanetti O, Frisoni GB. Specific EEG changes associated with atrophy of hippocampus in subjects with mild cognitive impairment and Alzheimer's disease. Int J Alzheimers Dis. 2012;2012:253153.

109. Moretti DV, Zanetti O, Binetti G, Frisoni GB. Quantitative EEG markers in mild cognitive impairment: degenerative versus vascular brain impairment. Int J Alzheimers Dis. 2012;2012:917537.

110. Moretti DV, Paternicò D, Binetti G, Zanetti O, Frisoni GB. Analysis of grey matter in thalamus and basal ganglia based on EEG $\alpha 3 / \alpha 2$ frequency ratio reveals specific changes in subjects with mild cognitive impairment. ASN Neuro. 2012;4(7):e00103.

111. Moretti DV, Paternico' D, Binetti G, Zanetti O, Frisoni GB. Relationship between EEG A3/ $\alpha 2$ ration and the nuclues accumbens in subjects with mild cognitive impairment. J Neurol Neurophysiol. 2013; $4(2): 1-6$

112. Moretti DV, Paternicò D, Binetti G, Zanetti O, Frisoni GB. Theta/ gamma frequency ratio is associated to grey matter changes in basal ganglia in subjects with mild cognitive impairment. J Radiol Diagnostic Imaging. 2013;52(1):10-18.

113. Moretti DV, Paternico D, Binetti G, Zanetti O, Frisoni GB. Temporoparietal brain network impairment is related To EEG A3/A2 power ratio in prodromal Alzheimer's disease. J Neurol Neurophysiol. 2013; 4(160):1-9

114. Moretti DV, Paternicò D, Binetti G, Zanetti O, Frisoni GB. EEG upper/ low alpha frequency power ratio relates to temporo-parietal brain atrophy and memory performances in mild cognitive impairment Front Aging Neurosci. 2013;5:63.

115. Moretti DV, Prestia A, Binetti G, Zanetti O, Frisoni GB. Increase of theta frequency is associated with reduction in regional cerebral blood flow only in subjects with mild cognitive impairment with higher upper alpha/low alpha EEG frequency power ratio. Front Behav Neurosci. 2013;7:188.

116. Moretti DV, Prestia A, Binetti G, Zanetti O, Frisoni GB. Correlation between regional cerebral blood flow and EEG upper/low alpha frequency power ratio in mild cognitive impairment. J Radiol Diagnostic Imaging. 2013;1(2):49-59.

117. Moretti DV, Paternicò D, Binetti G, Zanetti O, Frisoni GB. Electroencephalographic upper/low alpha frequency power ratio relates to cortex thinning in mild cognitive impairment. Neurodegener Dis. 2014;14(1):18-30.

118. Klimesch W, Doppelmayr M, Hanslmayr S. Upper alpha ERD and absolute power: their meaning for memory performance. Prog Brain Res. 2006;159:151-165. 
119. Klimesch W, Sauseng P, Hanslmayr S. EEG alpha oscillations: the inhibition timing hypothesis. Brain Res Rev. 2007;53(1):63-88.

120. Nunez P. Generation of human EEG rhythms by a combination of long and short-range neocortical interactions. Brain Topogr. 1989;1(3): 199-215.

121. Moretti DV. Atrophy and lower regional perfusion of temporoparietal brain areas are correlated with impairment in memory performances and increase of EEG upper alpha power in prodromal Alzheimer's disease. Am J Neurodegener Dis. 2015;4(1):13-27.

122. Moretti DV. Association of EEG, MRI, and regional blood flow biomarkers is predictive of prodromal Alzheimer's disease. Neuropsychiatr Dis Treat. 2015;11:2779-2791.

123. Moretti DV. Conversion of mild cognitive impairment patients in Alzheimer's disease: prognostic value of A3/ $\alpha 2$ electroencephalographic rhythms power ratio. Alzheimers Res Ther. 2015;7(1):80.
124. Moretti DV. Mild cognitive impairment: structural, metabolical, and neurophysiological evidence of a novel EEG biomarker. Front Neurol. 2015;6:152.

125. Moretti DV, Babiloni C, Binetti G, et al. Individual analysis of EEG frequency and band power in mild Alzheimer's disease. Clin Neurophysiol. 2004;115(2):299-308.

126. Stam CJ, Montez T, Jones BF, et al. Disturbed fluctuations of resting state EEG synchronization in Alzheimer's disease. Clin Neurophysiol. 2005;116(3):708-715.

127. Moretti DV, Benussi L, Fostinelli S, Ciani M, Binetti G, Ghidoni R. Progranulin mutations affects brain oscillatory activity in frontotemporal dementia. Front Aging Neurosci. 2016;8:35.
Clinical Interventions in Aging

\section{Publish your work in this journal}

Clinical Interventions in Aging is an international, peer-reviewed journal focusing on evidence-based reports on the value or lack thereof of treatments intended to prevent or delay the onset of maladaptive correlates of aging in human beings. This journal is indexed on PubMed Central, MedLine,

\section{Dovepress}

CAS, Scopus and the Elsevier Bibliographic databases. The manuscript management system is completely online and includes a very quick and fair peer-review system, which is all easy to use. Visit http://www.dovepress. com/testimonials.php to read real quotes from published authors. 